\title{
The Need for Qualitative Methods in Undergraduate IS Education
}

\author{
Albert S. M. Tay \\ Neumann University, Aston, Pennsylvania, USA
}

taya@neumann.edu

\begin{abstract}
Many of the Information Systems (IS) programs in the universities within the United States are rapidly changing their curriculum to make it more attractive to students. Some universities have reduced the major requirements from thirty credit hours to eighteen credit hours. The IS 2010 Curriculum Guideless and its predecessors have stressed that business related courses will continue to be the primary domain for IS curriculum. The changes in the program requirements might be more attractive to students but would the graduate be equipped with the needed knowledge and abilities to work in IS arena.
\end{abstract}

IS students in Systems and Analysis Design and Human Computer Interaction courses are illequip to utilize qualitative methods to gather and analyze users' requirement.

This exploratory study examines the need for the inclusion of non-core courses like qualitative methods and analysis course in to the IS curriculum. The study finds that ninety-one percent of the IS program of studies surveyed require only one elementary statistics course that does not include qualitative methods and analysis. The result suggests that qualitative methods and analysis ought to be considered as a non-core course in IS undergraduate curriculum.

Keywords: Undergraduate IS Curriculum, Qualitative Methods.

\section{Introduction}

The curriculum for Information Systems (IS) programs is in a flux presently owing to the much reduced enrollment across the nation. Students are simply shying away from IS programs. Even the prediction that there will be a great demand for IS-related jobs in the near future (U.S. Bureau of Labor Statistics, 2010) failed to increase enrolment in IS program across the United States. IS departments re-examined their programs and in some instances re-packaged their entire program to make it more attractive to students.

With the changes in the curriculum, IS departments might also want to re-examine non-IS courses in their curriculum. A course that should be given more consideration is the qualitative research

Material published as part of this publication, either on-line or in print, is copyrighted by the Informing Science Institute. Permission to make digital or paper copy of part or all of these works for personal or classroom use is granted without fee provided that the copies are not made or distributed for profit or commercial advantage AND that copies 1) bear this notice in full and 2) give the full citation on the first page. It is permissible to abstract these works so long as credit is given. To copy in all other cases or to republish or to post on a server or to redistribute to lists requires specific permission and payment of a fee. Contact Publisher@InformingScience.org to request redistribution permission. methods course. IS students in Systems and Analysis Design and Human Computer Interaction courses are illequipped to utilize qualitative methods to gather and analyze users’ requirement. Gathering and analyzing users’ requirements is a critical step in the whole system design life cycle. Failure to correctly gather and analyze the users requirements would result in costly de- 
lays or failure of the entire system or project.

This exploratory paper examines the need for the inclusion of qualitative methods course in the undergraduate IS curriculum.

\section{Literature Review}

The need for an IS curriculum is greater in the 1980s than when it was first outlined in the position paper by a committee of the ACM (Nunamaker, Couger, \& Davis, 1982). Even though the curriculum recommendations have expanded over the years, the motivations for the 1982-revised curriculum built upon those that motivated earlier curriculum efforts. The expansion takes into consideration changes in the importance of information systems, advances in technology, improvements in information systems analysis and development processes, and an increased need for information systems management skills.

Nunamaker et al. (1982) stress that in order for the information systems community to face the current and future demands; the curriculum should address the basic goals of people needs, skill needs, and tool needs. Furthermore, the basic philosophy of the IS program is based on the premise that graduates of the program will be employed for major segments of their careers in positions involving organizational information systems. They will

- Assist in defining and planning information systems

- Elicit information requirements for applications and assist in designing the systems

- Implement information systems applications

- Manage information system development and operation.

All aspects of the global computing field continue to face rapid and frequent changes. As a result, university-level Information Systems curricula need frequent updating to remain effective. The IS 2010 Curriculum Guidelines for Undergraduate Degree Programs in Information Systems is the latest curriculum recommendation. The IS 2010 Curriculum Guidelines has four broad key characteristics that shape the outcome significantly.

"First, the curriculum reaches beyond the schools of business and management. Second, the outcome expectations of the curriculum have been very carefully reevaluated and articulated first in the form of high-level IS capabilities and then in three knowledge and skills categories. Third, the curriculum is structured so that it separates the core of the curriculum from electives with the intent of supporting the concept of career tracks. Finally, the design of this curriculum includes enough flexibility to allow its adoption in a variety of educational system contexts.” (Topi, et al., 2010. p. vii)

The IS 2010 Curriculum Guidelines states the following as one of its key principles that guided the report is that "The model curriculum should be designed to help Information Systems programs to produce competent and confident entry-level graduates well suited to workplace responsibilities or further studies of Information Systems” (Topi, et al., 2010). As such the knowledge and skills of an IS graduate should include:

“Analytical and critical thinking, including creativity and ethical analysis.” Strong analytical and critical thinking skills are a foundation for everything IS professionals do - it is essential that they are able to systematically analyze complex systems and situations, break them down into manageable components, understand deep connections within sys- 
tems, and create solutions based on the results of a systematic analysis. Problem solving is omnipresent in the life of IS professionals. Capabilities should include:

1. Analyzing the ethical and legal implications of complex situations

2. Analyzing the risks associated with complex systems

3. Solving complex problems

4. Using quantitative analysis techniques appropriately and effectively

5. Enhancing innovation and creativity in oneself and others (Topi, et al., 2010. p. 21-22).

Table 1 consists of an abbreviated list of needed knowledge and abilities adapted from the 1972 Curriculum Report (Ashenhurst, 1972). These abilities and knowledge have not changed much over time and in the different curriculum revisions. The abilities and knowledge listed in Table 1 requires an IS graduate to perform qualitative analysis for data that has been gathered.

Table 1. Needed Knowledge and Abilities for Working Effectively in Information Systems

People

- Ability to describe individual and group behavior and to predict likely alternative future behavior in terms of commonly used variables of psychology and economics

- Ability to describe and predict task-oriented, time-constrained behavior in an organizational setting Systems

- Ability to view, describe, and define any situation as a system—specifying components, boundaries, and so forth

Computers

- Ability to develop several logical structures for a specified problem

- Ability to develop specifications for a major programming project in terms of functions, modules, and interfaces

- Ability to develop the major alternatives (assuming current technology) in specifying an information processing system, including data files and communications structures, to the level of major system components

- Ability to develop specifications for the computer-based part of a major information system, with details of task management and database management components

Organizations

- Ability to identify in an ongoing organizational situation the key issues and problems of each functional area

- Ability to identify information needs appropriate to issues and roles

- Knowledge of techniques for gathering information

- Ability to gather information systematically within an organization given specified information needs and/or specified information flows

- Ability to specify, given information needs and sources, several alternative sets of information transfers and processing to meet needs

- Ability to develop specifications for a major information system, addressing a given organizational need, and to determine the breakdown into manual and computer-based parts 


\section{System Analysis and Design Course}

The Systems Analysis and Design course textbooks have a chapter devoted to determining system requirements or information gathering. Kendall and Kendall (2010) devote two chapters to information gathering. It includes a subsection on “Analyzing Qualitative Documents”. This subsection states, "Many of these documents are rich in details ... many systems analysts are apprehensive about analyzing qualitative documents” (Kendall \& Kendall, 2010, p. 140).

Hoffer, George, and Valacich (2011 p. 162) at the onset of the "Analysis" section of the book stress that "Information...must be organized for analysis and design. Organizing, or structuring, system requirements results in diagrams and descriptions (model) that can be analyzed to show deficiencies, inefficiencies, missing elements, and illogical component of the ...information systems.” The book has a chapter on determining system requirements. This chapter covers the traditional methods and contemporary methods of determining system. It discusses about interviewing individuals, groups, and observation but the chapter did not discuss what to do with the data gathered from these interviews and observation.

In the following chapter, Hoffer, George, and Valacich (2011, p. 200) state that chapter's "focus will be on one tool that is used to coherently represent the information gathered as part of the requirements determination.” Hoffer, George, and Valacich assume that students will know how to sift through the qualitative data obtained from the interviews, document analysis, and observations.

\section{Human Computer Interaction Course}

The Human Computer Interaction (HCI) course textbooks devote chapters of the text to data gathering; data analysis, interpretation, and presentation; identifying needs and requirements; evaluation; and usability testing. Leventhal and Barnes (2008) and Sharp, Rogers, and Preece (2007) spend significant portion of their text discussing about performing qualitative analysis. Sharp, Rogers, and Preece (2007) have seven chapters out of 15 devoted to how to gather, analyze and present data for interaction design. These methods and approaches for analysis, interpretation, and presentation of data include: three simple types of qualitative analysis, tools to support data analysis, using theoretical frameworks, scenarios, use cases, essential use cases, task analysis, etc.

Though HCI course introduces students to qualitative data analysis, it is often not part of IS curriculum.

\section{Statistics Course}

Most universities require their students to take at least a course in elementary statistics. Each year thousands of high school students take for college credit the College Board Advance Placement Program in Statistics. The purpose of the AP course in statistics is to introduce students to the major concepts and tools for collecting, analyzing, and drawing conclusions from data. Students are exposed to four broad conceptual themes:

1. Exploring Data: Describing patterns and departures from patterns

2. Sampling and Experimentation: Planning and conducting a study

3. Anticipating Patterns: Exploring random phenomena using probability and simulation

4. Statistical Inference: Estimating population parameters and testing hypotheses

For further details of these four themes refer to the Appendix. 
Students who have taken a course in statistics would be able to use quantitative analysis techniques appropriately and effectively. However, they would have very little to no exposure to qualitative methods and analysis. If the students are exposed to qualitative methods it is on a very superficial level. Students will not be able to sift through the qualitative data obtained from the interviews, document analysis, and observations. Hence, the comments by Kendall \& Kendall (2010, p. 140) "many systems analysts are apprehensive about analyzing qualitative documents.”

\section{Method}

Utilizing the list of U.S. Universities by state found on http://www.utexas.edu/world/univ/state/, the author randomly selected universities within each state. If a state has less than ten universities then every third university is examined. Otherwise every fifth university is selected and search if the university has an IS program. If the university has an IS program within the college or school of business, the author would then further search for the program of study for an undergraduate degree in IS. The program of study lists all the general education courses, elective courses, core business courses, and the major courses.

The programs of study gathered are for the academic year 2010-11.

\section{Results}

A total of 47 IS programs of study in universities across the United States are gathered. 43 or 91.5 $\%$ universities surveyed require a course or three credits in statistics. One university requires no coursework in statistics. Three universities require two courses or six credits in statistics. Table 2 is a graphical depiction of the results.

Table 2: Number of Statistical Course Required

\begin{tabular}{|c|c|}
\hline $\begin{array}{l}\text { Number of Statistical } \\
\text { course required }\end{array}$ & Number of Universities \\
\hline 0 & 1 \\
\hline 1 & 43 \\
\hline 2 & 3 \\
\hline
\end{tabular}

The description for the statistics course for many of the university is very similar to the four themes as outlined by the College Board Advance Placement Program for Statistics (refer appendix A). One of the few exceptions is the description for the Business Statistics course at Bentley University (2010):

"This course develops the basic descriptive and inferential statistical concepts and techniques useful in making a wide range of business decisions. Topics include graphical and numerical techniques for summarizing and describing qualitative and quantitative data; ... An introduction to random sampling and sampling distributions will be presented along with a discussion of the common statistical inference techniques used to analyze the sample data. Specific inferential topics include confidence intervals, hypothesis testing and regression analysis. The use of Excel for analyzing qualitative and quantitative data sets will be integrated throughout the course material.” 


\section{Conclusion and Implications}

IS departments are re-examining their programs and in some instances re-packaging their entire program to make it more attractive to students. Ninety-one percent of the IS program of studies surveyed requires only one elementary statistics course that does not include qualitative methods and analysis. IS students in Systems and Analysis Design and Human Computer Interaction courses are ill-equipped to utilize qualitative methods to gather and analyze users' requirement. Gathering and analyzing users' requirements is a critical step in the whole system design life cycle. Failure to correctly gather and analyze the users requirements would result in costly delays or failure of the entire system or project.

The students in Systems and Analysis Design and Human Computer Interaction courses are illequipped to perform qualitative data gathering and analysis. When these students graduate from IS programs they will not be able to:

(i) gather information systematically within an organization given specified information needs and/or specified information flows,

(ii) specify, given information needs and sources, several alternative sets of information transfers and processing to meet needs, and

(iii)develop specifications for a major information system, addressing a given organizational need, and to determine the breakdown into manual and computer-based parts.

The IT Workforce Trends: Implications for Curriculum and Hiring (Bullen, Abraham, Gallagher, Simon, \& Zwieg, 2009) indicates that a looming crisis in several areas: 1) graduates who are not trained in areas that the marketplace is seeking; 2) thin pipeline for specific technical skills; 3) increasing pressure to source IT capability; and 4) lag in university responsiveness to the needs of the marketplace.

The Occupational Outlook Handbook (2010) predicts that computer applications software engineers also are expected to grow rapidly from 2008 to 2018. Expanding Internet technologies have spurred demand for these workers, who can develop Internet, intranet, and Web applications.

The IT Workforce Trends, the anticipated increase in demand for computer applications software engineers coupled with falling enrolments in IS programs may result in IS graduates that are unprepared to perform at the level that is expected of them by their future employers.

Many IS programs within the United States are rapidly changing their curriculum to make it more attractive to students. Departments like the Computer Information Systems program at Idaho State University $(2008,2009)$ have reduced the major requirements from thirty credit hours to eighteen credit hours as well as total number of credit hours required for graduation. The IS 2010 Curriculum Guideless is an excellent report that deals with the rapid and frequent changes in the technology field. The report stresses that business related courses will continue to be the primary domain for IS curriculum (Topi, et al., 2010). The IS 2010 identifies prerequisite skills needed by all students. One of the skills is statistical analysis. Based on the curriculum for the statistical analysis course, it is clear that qualitative analysis is not included. The inclusion of non-core courses like qualitative research methods and analysis course should be evaluated. Qualitative research methods and analysis course merits a place in the non-core IS undergraduate curriculum.

\section{Future Directions}

The study points out that most IS program lack a qualitative methods and analysis portion in the statistics course. If more programs of study are included in future studies, both in the United States and worldwide it may provide a stronger impetus to include qualitative research methods in the IS program of study for undergraduates. In addition to examining programs of study, future 
studies could include interviews with faculty, students or employers to provide richer data and more significant conclusions.

Future studies could be expanded to study the changes in programs of study from year to year. In this study, the programs of study examined are for the academic year 2010-11. Future studies should compare the programs of study in various academic years.

\section{References}

Ashenhurst, R. (1972). Curriculum recommendations for graduate professional programs in information systems. Communications of the ACM, 15(5), 364-398.

Bentley University. (2010). Undergraduate catalogue 2010-2011. GB 210 Business Statistics course description.

Bullens, C. V., Abraham, T., Gallagher, K., Simon, J. C., \& Zwieg, P. (2009). IT workforce trends: Implications for curriculum and hiring. Communications of the Association for Information Systems, 24(9), 129-140.

Central Board Advance Placement Program for Statistics. (2009). Statistics course description.

Hoffer, J. A., George, J. F., \& Valacich, J. S. (2011). Modern systems analysis and design (6th ed.). Upper Saddle River, NJ: Prentice Hall.

Idaho State University. (2009). Idaho State University undergraduate catalog 2009-2010.

Idaho State University. (2010). Idaho State University undergraduate catalog 2010-2011.

Kendall, K. E., \& Kendall, J. E. (2011). Systems analysis and design (8th ed.). Upper Saddle River, NJ: Prentice Hall.

Leventhal, L., \& Barnes, J. (2008). Usability engineering: Process, products \& examples. Upper Saddle River, NJ: Prentice Hall.

Nunamaker, J. F., Couger, J. D., \& Davis, G. B. (1982). A report of the ACM curriculum committee on information systems. Communications of the ACM, 25(11), 781-805.

Sharp, H., Rogers, Y., \& Preece, J. (2007). Interaction design: Beyond human-computer interaction (2nd ed.) Hoboken, NJ: John Wiley \& Sons.

Topi, H., Valacich, J. S., Wright, R. T., Kaiser, K., Nunamaker, Jr., J. F., Sipior, J. C., \& de Vreede, G. J. (2010). IS 2010: Curriculum guidelines for undergraduate degree programs in information systems. Communications of the Association for Information Systems, 26(18).

U.S. Bureau of Labor Statistics. (2010). Occupational outlook handbook.

\section{Appendix: \\ Central Board Advance Placement Program for Statistics - Statistics Course Description May 2009, May 2010.}

The purpose of the AP course in statistics is to introduce students to the major concepts and tools for collecting, analyzing, and drawing conclusions from data. Students are exposed to four broad conceptual themes:

1. Exploring Data: Describing patterns and departures from patterns

2. Sampling and Experimentation: Planning and conducting a study

3. Anticipating Patterns: Exploring random phenomena using probability and simulation

4. Statistical Inference: Estimating population parameters and testing hypotheses 
I. Exploring Data: Describing patterns and departures from patterns Exploratory analysis of data makes use of graphical and numerical techniques to study patterns and departures from patterns. Emphasis should be placed on interpreting information from graphical and numerical displays and summaries.

A. Constructing and interpreting graphical displays of distributions of univariate data (dotplot, stemplot, histogram, cumulative frequency plot)

1. Center and spread

2. Clusters and gaps

3. Outliers and other unusual features

4. Shape

B. Summarizing distributions of univariate data

1. Measuring center: median, mean

2. Measuring spread: range, interquartile range, standard deviation

3. Measuring position: quartiles, percentiles, standardized scores (z-scores)

4. Using boxplots

5. The effect of changing units on summary measures

C. Comparing distributions of univariate data (dotplots, back-to-back stemplots, parallel boxplots)

1. Comparing center and spread: within group, between group variation

2. Comparing clusters and gaps

3. Comparing outliers and other unusual features

4. Comparing shapes

D. Exploring bivariate data

1. Analyzing patterns in scatterplots

2. Correlation and linearity

3. Least-squares regression line

4. Residual plots, outliers, and influential points

5. Transformations to achieve linearity: logarithmic and power transformations

E. Exploring categorical data

1. Frequency tables and bar charts

2. Marginal and joint frequencies for two-way tables

3. Conditional relative frequencies and association

4. Comparing distributions using bar charts

II. Sampling and Experimentation: Planning and conducting a study

Data must be collected according to a well-developed plan if valid information on a conjecture is to be obtained. This plan includes clarifying the question and deciding upon a method of data collection and analysis.

A. Overview of methods of data collection

1. Census

2. Sample survey

3. Experiment

4. Observational study

B. Planning and conducting surveys

1. Characteristics of a well-designed and well-conducted survey

2. Populations, samples, and random selection

3. Sources of bias in sampling and surveys

4. Sampling methods, including simple random sampling, stratified random sampling, and cluster sampling

C. Planning and conducting experiments

1. Characteristics of a well-designed and well-conducted experiment

2. Treatments, control groups, experimental units, random assignments, and replication

3. Sources of bias and confounding, including placebo effect and blinding

4. Completely randomized design

5. Randomized block design, including matched pairs design

D. Generalizability of results and types of conclusions that can be drawn from observational studies, experiments, and surveys 
III. Anticipating Patterns: Exploring random phenomena using probability and simulation Probability is the tool used for anticipating what the distribution of data should look like under a given model.

A. Probability

1. Interpreting probability, including long-run relative frequency interpretation

2. "Law of Large Numbers" concept

3. Addition rule, multiplication rule, conditional probability, and independence

4. Discrete random variables and their probability distributions, including binomial and geometric

5. Simulation of random behavior and probability distributions

6. Mean (expected value) and standard deviation of a random variable, and linear transformation of a random variable

B. Combining independent random variables

1. Notion of independence versus dependence

2. Mean and standard deviation for sums and differences of independent random variables

C. The normal distribution

1. Properties of the normal distribution

2. Using tables of the normal distribution

3. The normal distribution as a model for measurements

D. Sampling distributions

1. Sampling distribution of a sample proportion

2. Sampling distribution of a sample mean

3. Central Limit Theorem

4. Sampling distribution of a difference between two independent sample proportions

5. Sampling distribution of a difference between two independent sample means

6. Simulation of sampling distributions

7. t-distribution

8. Chi-square distribution

IV. Statistical Inference: Estimating population parameters and testing hypotheses

Statistical inference guides the selection of appropriate models.

A. Estimation (point estimators and confidence intervals)

1. Estimating population parameters and margins of error

2. Properties of point estimators, including unbiasedness and variability

3. Logic of confidence intervals, meaning of confidence level and confidence intervals, and properties of confidence intervals

4. Large sample confidence interval for a proportion

5. Large sample confidence interval for a difference between two proportions

6. Confidence interval for a mean

7. Confidence interval for a difference between two means (unpaired and paired)

8. Confidence interval for the slope of a least-squares regression line

B. Tests of significance

1. Logic of significance testing, null and alternative hypotheses; p-values; one- and two-sided tests; concepts of Type I and Type II errors; concept of power

2. Large sample test for a proportion

3. Large sample test for a difference between two proportions

4. Test for a mean

5. Test for a difference between two means (unpaired and paired)

6. Chi-square test for goodness of fit, homogeneity of proportions, and independence (one- and two-way tables)

7. Test for the slope of a least-squares regression line 


\section{Biography}

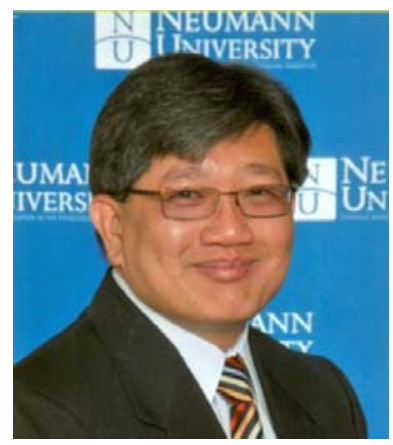

Dr. Albert Tay is an Assistant Professor of Computer Information Management at Neumann University. His areas of research interest include Global Information Systems, Organizational Impact of IT, Software Development and Support, and Technology Adoption. He has a BS in Information Systems from Brigham Young University-Hawaii (1992), a MS in Decision and Information Systems from Arizona State University (1993), and a PhD in Communication and Information Sciences from University of Hawaii at Manoa (2006). Albert has over six years of IT management experience with organizations such as Adaptec Inc, Applied Materials Inc., and Koeneman Capital Management. 